\title{
Pendugaan Penurunan Kandungan Asam Askorbat Brokoli(Brasisca oleracea Var. Italica) Selama Penyimpanan Dingin Menggunakan Pendekatan Persamaan Arrhenius (Establishment Of Ascorbic acid Of Broccoli (Brassica oleracea Var. Italica)
}

\section{,During Storage With Arrhenius Approach)}

\author{
Abu Bakar ${ }^{1}$, Kiman Siregar', Ratna ${ }^{1 *}$ \\ ${ }^{1}$ Program studi Teknik Pertanian, Fakultas Pertanian, Universitas Syiah Kuala \\ *Corresponding author: ratna@unsyiah.ac.id
}

\begin{abstract}
Abstrak. Menganalisis mutu selama penyimpanan dapat dilakukan dengan mengendalikan kondisi penyimpanan tertentu serta menduga laju penurunan mutu yang terjadi. Penelitian ini bertujuan untuk menduga penurunan kandungan asam askorbat (Brassica oleracea Var. Italica) selama penyimpanan mengunakan pendekatan persamaan Arrhenius. Brokoli disimpan dengan variasi suhu yaitu suhu $5{ }^{\circ} \mathrm{C}, 10^{\circ} \mathrm{C}$, dan $20^{\circ} \mathrm{C}$. Analisis dilakukan 3 hari sekali hingga panelis menolak dengan parameter susut bobot, tingkat kekerasan, Klorofil, Kalsium, vitamin C (Asam Asam dan uji organoleptik yaitu warna, rasa, aroma dan tekstur.Model Arrhenius berdasarkan kandungan vitamin C (asam askorbat) menghasilkan umur simpan pada brokoli yaitu pada suhu $5^{\circ} \mathrm{C}$ dengan kemasan adalah 21 hari dengan nilai $\mathrm{R}^{2}$ adalah 0,97 , pada suhu $10^{\circ} \mathrm{C}$ dengan kemasan didapatkan umur simpan 21 hari dengan nilai $\mathrm{R}^{2}$ adalah 0,98 , pada suhu $20^{\circ} \mathrm{C}$ didapatkan umur simpan yaitu 6 hari dengan nilai $\mathrm{R}^{2}$ adalah 0,97 . Perlakuan terbaik pada penelitian ini yang mampu mempertahankan mutu simpan brokoli dan memiliki umur simpan yang lama, yaitu penyimpanan pada suhu $5^{\circ} \mathrm{C}$ dengan berdasarkan parameter susut bobot terendah sebesar $11,5 \%$, tingkat kekerasan tertinggi sebesar $0,7 \mathrm{~kg} / \mathrm{cm}^{2}$, penyimpanan suhu $5^{\circ} \mathrm{C}$ dengan kemasan 21 hari penurunan kandungan vitamin $\mathrm{C}$ (asam askorbat) terendah yaitu 21,2 $\mathrm{mg}$, dan penurunan klorofil sebesar $0,35 \mathrm{mg} / \mathrm{lgr}$.
\end{abstract}

Keywor: Broccoli (Brasisca oleracea Var Italica), arrhenius and askobat acid.

\begin{abstract}
Analyzing quality during storage can be done by controlling certain storage conditions as well as suspecting the rate of degradation that occurs. This study aims to estimate the decrease in ascorbic acid content (Brassica oleracea Var Italica) during storage using the Arrhenius equation approach. Broccoli is stored with temperature variations of 5 ${ }^{\circ} \mathrm{C}, 10^{\circ} \mathrm{C}$, and $20^{\circ} \mathrm{C}$. Analysis is done every 3 days until panelist refused with weight loss parameter, hardness level, chlorophyll, calcium, vitamin $\mathrm{C}$ acid acid and organoleptic test that is color, flavor, aroma and texture. Arrhenius model based on vitamin $\mathrm{C}$ content (ascorbic acid) produces shelf life at broccoli ie at $5{ }^{\circ} \mathrm{C}$ with packing is 21 days with $\mathrm{R}^{2}$ value is 0.97 , at $10^{\circ} \mathrm{C}$ with packaging obtained by 21 days saving life with $\mathrm{R}^{2}$ value is 0.98 , at $20^{\circ} \mathrm{C}$ we have a shelf life of 6 days with $\mathrm{R}^{2}$ value is 0.97 . The best treatment in this study is able to maintain the quality of broccoli and has a long shelf life, ie storage at $5{ }^{\circ} \mathrm{C}$ based on the lowest weight loss parameter of $11.5 \%$, the highest hardness level of $0.7 \mathrm{~kg} / \mathrm{cm}^{2}$, storage temperature of $5^{\circ} \mathrm{C}$ with the 21 day packs of decrease in vitamin $\mathrm{C}$ content (ascorbic acid) the lowest is $212 \mathrm{mg}$, and the decrease of chlorophyll by $0.35 \mathrm{mg} / 1 \mathrm{gr}$.
\end{abstract}

Keywords: Broccoli (Brasisca oleracea Var Italica), arrhenius and askobat acid. 


\section{PENDAHULUAN}

Brokoli (Brasisca oleracea Var. Italica) merupakan salah satu komoditi jenis sayur-sayuran brokoli banyak dimanfaatkan sebagai sumber vitamin dalam kehidupan sehari-hari dimana sayuran ini banyak digemari masyarakat karena mengandung vitamin A dan Vitamin C (asam askorbat), mineral dan kalsium serta zat besi, sehingga permintaan bertambah. Setelah dilakukan pemanenan mutu brokoli tidak bisa diperbaiki tetapi hanya dapat memperlambat kerusakan atau penurunan mutunya. Mutu segar brokoli mudah mengalami kerusakan, karena produk masih melangsungkan aktivitas metabolisme seperti transpirasi, respirasi yaitu disebut juga kerusakan internal bahan dan kerusakkan mekanis yang dibabkan oleh gesekan yaitu disebut kerusak eksternal. Untuk menduga umur simpan kita dapat menggunakan permodelan agar lebih mudah dalam mempelajari umur simpan suatau komoditi. Model adalah suatu penggambaran sistem sehingga kita dapat memahaminya secara lebih jelas, model juga berarti penyederhanaan. Salah satu tujuan dari data permodelan adalah pendugaan atau peramalan. Dalam pendugaan ini, kita akan memperkirakan apa yang terjadi diwaktu mendatang, agar manusia dapat mengantisipasi akibat yang akan terjadi.

\section{Tujuan Penelitian}

Tujuan dari penelitian ini adalah untuk menduga penurunan kandungan asam askorbat brokoli (Brassica oleracea Var. Italica) selama penyimpanan menggunakan pendekatan persamaan Arrhenius

\section{Rumusan Masalah}

Selama ini masih banyak masyarakat yang memanen brokoli dengan tidak memperhitungkan umur panen yang benar, dan cara memilih suhu yang tepat untuk penyimpanan brokoli itu sendiri. Sehingga dalam menduga umur simpan tidak dapat diprediksi. Hal ini berpengaruh pada umur simpan brokoli tidak bertahan lama, oleh karena itu perlu dilakukan penelitian agar didapatkan pendugaan umur simpan yang optimal dan suhu penyimpanan yang tepat untuk komoditi brokoli.

\section{Manfaat Penelitian}

Manfaat dari penelitian ini diharapkan dapat digunakan sebagai sarana pengembangan ilmu pengetahuan dalam mermpertahankan kesegaran brokoli dan kandungan gizi yang terdapat pada brokoli.

\section{Metode Penelitian}

Penelitian yang dilaksanakan pada bulan Februari sampai bulan Mei 2017. Penelitian ini dilaksanakan di Laboratorium Teknik Pasca Panen Program Studi Teknik Peratanian dan Laboratorium Teknologi Hasil Pertanian, Fakultas Pertanian Universitas Syiah Kuala.

\section{Alat dan Bahan Penelitian}

Alat-alat yang digunakan dalam penelitian ini yaitu: lemari es, bascom, Hardness Tester, termometer, timbangan. Bahan-bahan yang digunakan adalah: Brokoli yang diperoleh dari petani sumatera utara dan Plastik Stretch Film.

\section{Prosedur Penelitian}

Penelitian ini menggunakan brokoli dari Balai Pelatihan Penelitian Budidaya Tanaman Sayuran Berastagi, Kecamatan Brastagi, Kabupaten Karo, Provinsi Sumatera Utara dengan kriteria 
panen dengan berat sekitar 300-500 g, diameter $10 \mathrm{~cm}$, panjang tangkai $13 \mathrm{~cm}$ setelah dipanen dimasukan ke dalam Styrofoam Box yang diberikan lapisan es diangkut dengan menempuh jalur darat selama 12 jam menuju Banda Aceh atau tempat penelitian setelah itu baru dilakukan sortasi untuk memisah brokoli yang kotor, rusak dan busuk. Kemudian diberikan dua pelakuan yaitu dikemas menggunakan kemasan plastik Stretch Film dan tanpa kemasan. Kemudian Brokoli disimpan pada suhu $5^{\circ} \mathrm{C}, 10^{\circ} \mathrm{C}$ dan $20^{\circ} \mathrm{C}$. Pengamatan dilakukan setiap 3 hari sekali sampai panelis menolak. Parameter yang dianalisis adalah susut bobot, kandungan asam askorbat, Perhitungan beban Pendinginan internal bahan, Kalsium (mg), Klorofil (zat hijau daun), uji organoleptik yaitu warna, aroma, tekstur dan uji tingkat kekerasan.

\section{Prosedur Permodelan}

Persamaan Arrhenius menunjukkan ketergantungan laju reaksi deteriorasi terhadap suhu yang dirumuskan sebagai berikut :

$$
\mathrm{K}=\text { ko.e RT .... }
$$

Dimana : $\mathrm{K}=$ Konstanta penurunan mutu

Ko $=$ Konstanta (tidak tergantung pada suhu)

$\mathrm{Ea}=$ Energi aktivasi $(\mathrm{kal} / \mathrm{mol})$

$\mathrm{T}=$ Suhu mutlak $\left({ }^{\circ} \mathrm{K}\right)$

$\mathrm{R}=$ Konstanta gas $(1,986 \mathrm{kal} / \mathrm{mol} \mathrm{K})$

Demikian perhitungan umur simpan dapat dilakukan dengan menggunakan persamaan Arrhenius yang diperoleh tersebut.

\section{Analisis Data}

Susut Bobot

Susut Bobot $=($ Bobot Awal-Bobot Akhir $) /($ bobot Awal $) \times 100 \%$

\section{Uji Kadar Asam Askorbat}

Asam Askorbat $(\mathrm{mg} / 100 \mathrm{~g}$ bahan $)=((\mathrm{ml}$-iod. $0,01 \mathrm{~N}) \times 0,88 \times \mathrm{px} 100) /($ gram sampel $)$.

Keterangan : $\mathrm{P}=$ Faktor Pengecer

\section{Uji kadar Klorofil}

Klorofil total $(\mathrm{mg} / \mathrm{g})=(8.02 \times \mathrm{A} 663)+(20.2 \times \mathrm{A} 645) \times 10^{\wedge}-1$

Ket : A645 = absorbansi pada panjang gelombang $646 \mathrm{~nm}$

A663 = absorbansi pada panjang gelombang $663 \mathrm{~nm}$

\section{Perhitungan Beban Pendinginan Internal Bahan}

$$
\mathrm{QP}=\mathrm{m} . \mathrm{CP} . \Delta \mathrm{t}
$$

Dimana, $\mathrm{m}$ : berat produk $(\mathrm{kg})$

$\mathrm{CP}$ : panas jenis produk $\left(\mathrm{J} / \mathrm{kg} .{ }^{\circ} \mathrm{C}\right)$

$\Delta t$ : waktu pendinginan (detik) 


\subsubsection{Uji Kadar Kalsium}

$$
\% \mathrm{Ca}=((\mathrm{Vs}-\mathrm{VB}) \times \mathrm{N} \times 0.02 \times \mathrm{o}) /(\mathrm{W} \times \mathrm{A}) \times 100 \%(9)
$$

Keterangan: $\mathrm{Vs}=$ Volume Titrasi

$\mathrm{VB}=$ Volume Titrasi Blanko

$\mathrm{N}=$ Normalitas $\mathrm{KMnO} 44$

$\mathrm{A}=$ Berat Yang Diambil Dari Larutan Indukan

$\mathrm{W}=$ Berat Contoh

\section{Uji Organoleptik}

menyatakan bahwa uji organoleptik merupakan salah satu metode penilaian yang digunakan ini menggunakan tipe pengujian dengan uji scoring terhadap warna, aroma dan tekstur brokoli. Uji organoleptik terhadap brokoli ini dilakukan dengan bantuan 25 panelis tidak terlatih.

\section{Uji Kekerasan}

$$
\tau=(\mathrm{P} / \mathrm{A})
$$

Keterangan : $\tau=$ Tingkat kekerasan $\left(\mathrm{kg} / \mathrm{cm}^{2}\right)$

$\mathrm{P}=$ Gaya tekan dari hasil pembacaan alat $(\mathrm{kg})$

$\mathrm{A}=$ Luas alat penekan $\left(\mathrm{cm}^{2}\right)$. 


\section{Asam Askobat}

\section{HASIL DAN PEMBAHASAN}

Hasil penelitian kadar vitamin C (asam askorbat) awal (0 hari) adalah 96,8 mg. Hasil penelitian pada perlakuan dikemas suhu $5^{\circ} \mathrm{C}$ dengan lama penyimpanan 21 hari dan pada perlakuan dikemas suhu $10^{\circ} \mathrm{C}$ dengan lama lama pemyimpanan 21 hari terhadap penurunan kadar vitamin $\mathrm{C}$ (asam askorbat) lebih tinggi dari pada perlakuan dikemas suhu $5^{\circ} \mathrm{C}$ lama penyimpanan 21 hari. Hal tersebut menunjukkan bahwa perlakuan dikemas dan disimpan pada suhu $5^{\circ} \mathrm{C}$ adalah penurunan vitamin $\mathrm{C}$ yang terendah yaitu dapat menghambat laju respirasi atau proses penguapan pada bahan nilai kandungan kalsium pada brokoli. Brokoli yang disimpan pada suhu $20^{\circ} \mathrm{C}$ dengan lama penyimpanan 9 hari juga mengalami kebusukkan.

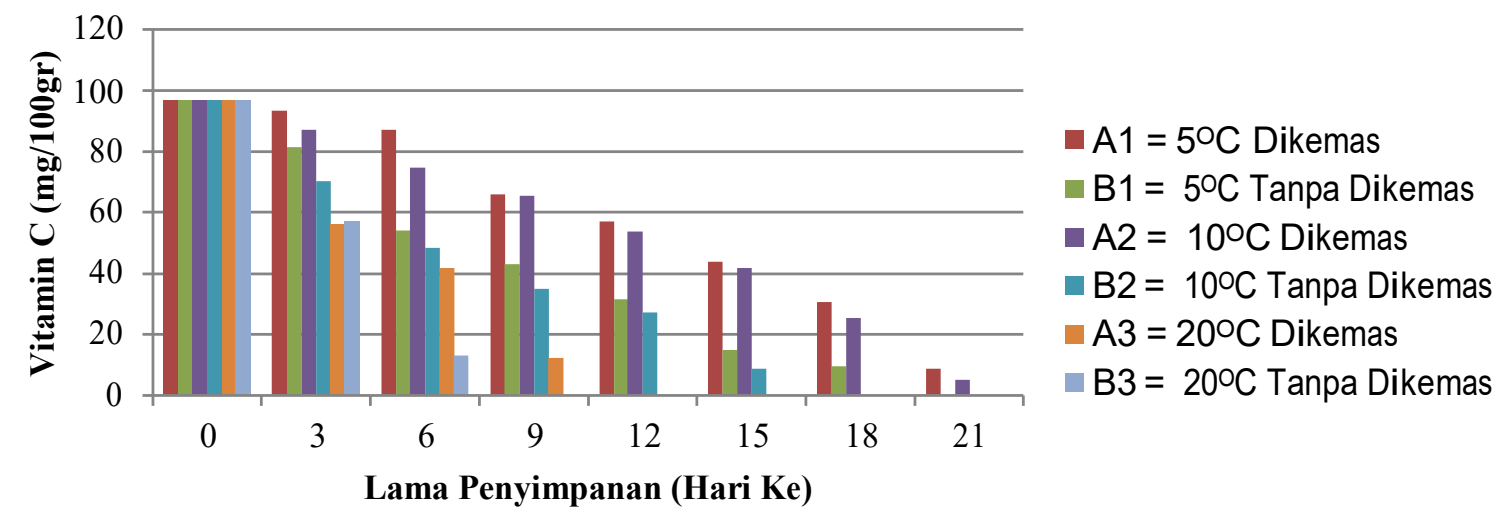

Gambar 6. Hubungan Vitamin C Brokoli dan Variasi perlakuan Suhu selama penyimpanan.

\section{Penentuan Umur Simpan Brokoli Berdasarkan Vitamin C (Asam askorbat)}

Menurut Haryadi (2006), metode Accelerad Shelf Life Testing (ASLT) dengan model Arrhenius umumny digunakan untuk melakukan pendugaan umur simpan produk pangan yang sensitif oleh perubahan suhu, di antaranya produk pangan yang mudah mengalami ketngikan (oksidasi lemak), perubahan warna oleh reaksi kecoklatan, atau kerusakan vitamin C. Oleh karena itu pada penelitian ini penentuan umur simpan dilakukan dengan persaamaan arrhenius yaitu, brokoli dengan perlakuan dikemas dan tanpa kemasan disimpan pada suhu yatu: $5^{\circ} \mathrm{C}, 10^{\circ} \mathrm{C}$ dan $20^{\circ} \mathrm{C}$. 


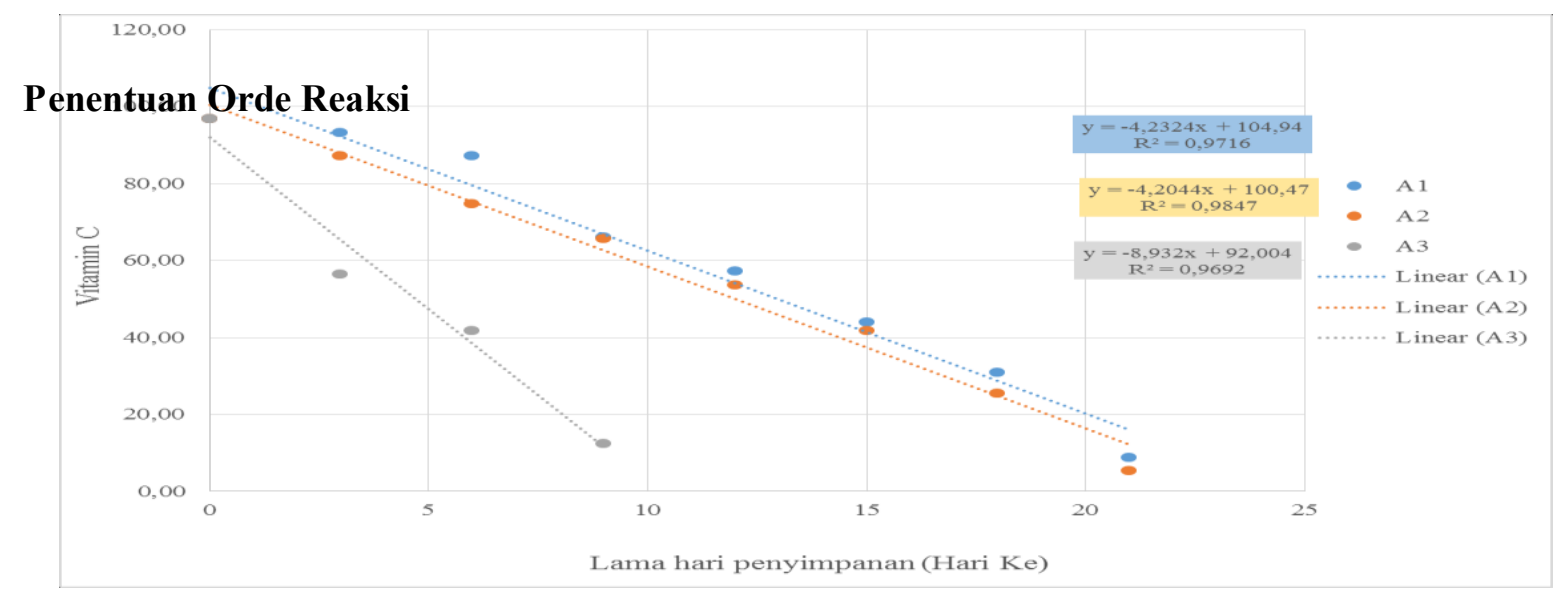

Gambar 1. Grafik plot orde nol brokoli dengan kemasan.

Data yang ditunjukkan pada Gambar 1 diketahui bahwa A1 (suhu $5^{\circ} \mathrm{C}$ dengan kemasan) orde nol persamaan garis $\mathrm{y}=-4,2324 \mathrm{x}+104,94$ dan nilai $\mathrm{R}^{2}=0,9716$.Pada perlakuan $\mathrm{A} 2$ (suhu $10^{\circ} \mathrm{C}$ dengan kemasan) persamaan garis $\mathrm{y}=-4,2044 \mathrm{x}+100,47$ dan nilai $\mathrm{R}^{2}=0,9847$. Selanjutnya pada perlakuan A3 (suhu $20^{\circ} \mathrm{C}$ dengan kemasan) persamaan garis $\mathrm{y}=-8,392 \mathrm{x}+$ 92,004 dan niali $\mathrm{R}^{2}=0.9692$.

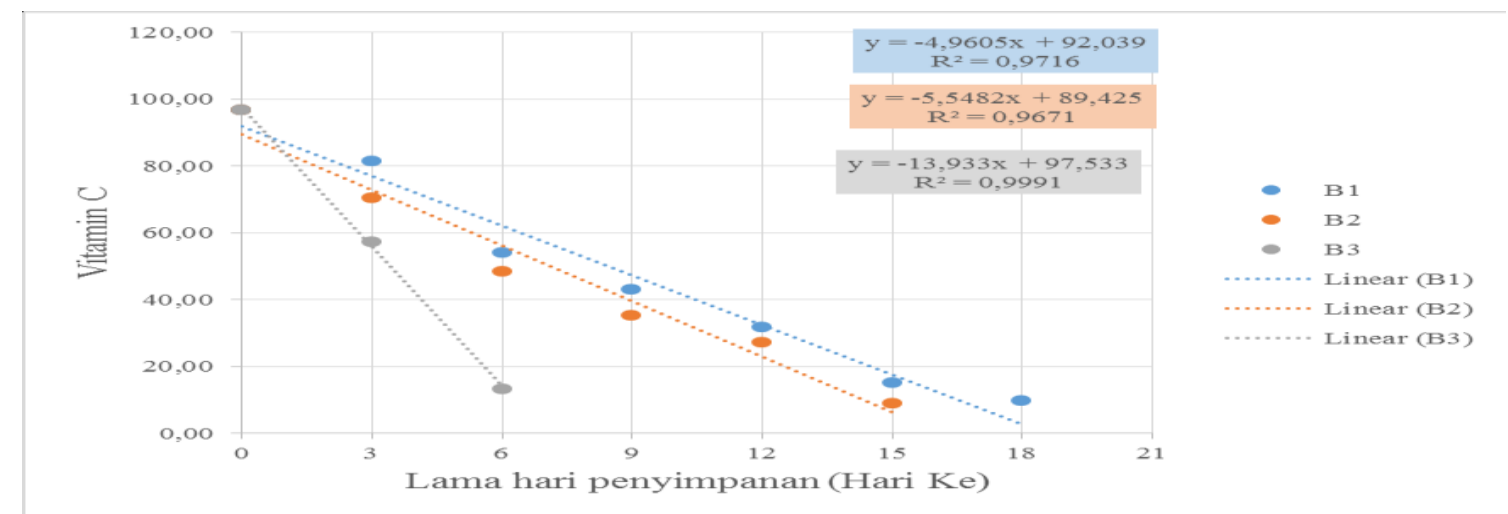

Gambar 16. Grafik plot orde nol brokoli tanpa kemasan.

Data yang ditunjukkan pada gambar 15 diketahui bahwa $\mathrm{B} 1$ (suhu $5^{\circ} \mathrm{C}$ tanpa kemasan) persamaan garis $\mathrm{y}=-4,9605 \mathrm{x}+92,039$ dan nilai $\mathrm{R}^{2}=0,9716$. Perlakuan $\mathrm{B} 2$ (suhu $10^{\circ} \mathrm{C}$ tanpa kemasan) dengan persamaan garis $\mathrm{y}=-5,5482+89,425$ dan nilai $\mathrm{R}^{2}=0,9671$. Pada perlakuan $\mathrm{B} 3$ (suhu $20^{\circ} \mathrm{C}$ tanpa kemasan) persamaan garis $\mathrm{y}=-13,933 \mathrm{x}+97,533$ dan nilai $\mathrm{R}^{2}=0,9991$.

\section{Perhitungan Nila k}

Pada dasarnya iketahui laju reaksi sangat dipengaruhi oleh suhu. Dalam medel arrhenius suhu merupakan faktor yang sangat berpengaruh terhadap penurunan mutu pangan. Semakin tingggi suhu, maka akan semakin tinggi pula laju reaksi dengan kata lain semakin tinggi nilai $\mathrm{T}$ maka semakin pula nilai $\mathrm{k}$. 
Tabel 1. Hubungan 1/T dengan nilai k pada brokoli dengan kemasan

\begin{tabular}{ccc}
\hline Perlakuan & Persamaan Garis & k (Slope Persamaan) \\
\hline $5^{\circ} \mathrm{C}$ & $\mathrm{y}=-4,2324 \mathrm{x}+104,94$ & 4,23 \\
$10^{\circ} \mathrm{C}$ & $\mathrm{y}=-4,2044 \mathrm{x}+100,47$ & 4,2 \\
$20^{\circ} \mathrm{C}$ & $\mathrm{y}=-8,932 \mathrm{x}+92,004$ & 8,93 \\
\hline
\end{tabular}

Tabel 2. Hubungan 1/T dengan nilai k pada brokoli tanpa kemasan

\begin{tabular}{clc}
\hline Perlakuan & \multicolumn{1}{c}{ Persamaan garis } & Slope persamaan $\mathrm{k}$ \\
\hline $5^{\circ} \mathrm{C}$ & $\mathrm{y}=-4,9605 \mathrm{x}+92,039$ & 4,96 \\
$10^{\circ} \mathrm{C}$ & $\mathrm{y}=-5,5482 \mathrm{x} x+89,425$ & 5,54 \\
$20^{\circ} \mathrm{C}$ & $\mathrm{y}=-13,933 \mathrm{x}+97,533$ & 13,93 \\
\hline
\end{tabular}

Data yang telah diperoleh pehitungan nilai $\mathrm{k}$ dari masing-masing perlakuan yang tertinggi terdapat pada perlakuan dengan kemasan dan disimpan pada suhu $20^{\circ} \mathrm{C}$. hal ini menunjukkan bahwa pada suhu $20^{\circ} \mathrm{C}$ terjadi penurunan kadar vitamin $\mathrm{C}$ (asam askorbat) yang lebih besar dari pada perlakuan dan suhu penyimpanan lainnya. Sedangkan pada suhu $5^{\circ} \mathrm{C}$ dengan perlakuan dikemas terdapat nilai terkecil dari pada suhu lain, yang berarti bahwa penurunan kadar vitamin $\mathrm{C}$ (asam askorbat) terendah. hal ini menunjukan semakin besar laju reaksi k maka akan semakin besar vitamin $\mathrm{C}$ (asam askorbat ) yang hilang dan semakin kecil nilai $\mathrm{k}$ maka semakin kecil mengalami penurunan.dapat disimpulkan bahwa penyimpan brokoli terbaik adalah perlakuan dengan kemasan dan disimpan pada suhu $5^{\circ} \mathrm{C}$.

\section{Model Umur simpan}

Nilai umur simpan bisa didapatkan pada temperatur lainnya yaitu dengan cara menghubungkan umur dengan temperatur. Nilai k yang telah diperoleh tersebut dihubungkan dengan temperatur dengan menggunakan persamaan arrhenius, yaitu sebagai berikut:Nilai k dan $1 / \mathrm{T}$ yang sudah diperoleh maka selanjutnya diplotkan pada grafik. Grafik dari hubungan $\mathrm{k}$ sebagai koordinat y dengan $1 / \mathrm{T}$ sebagai absis $\mathrm{x}$, akan memberikan persamaan garis lurus $\mathrm{y}=\mathrm{ax}+\mathrm{b}$. Untuk $\mathrm{Ea} / \mathrm{R}$ sama dengan a sedangkan untuk $\mathrm{k} 0$ sama dengan $\mathrm{b}$. Grafik hubungan $\mathrm{k}$ dan $1 / \mathrm{T}$ pada brokoli dapat dilihat pada tabel.

Tabel 3. Hubungan1/T dengan nilai k pada brokoli dengan kemasan

\begin{tabular}{cccccc}
\hline Perlakuan & Suhu ${ }^{0} \mathrm{C}$ & kelvin & $1 / \mathrm{T}$ & $\mathrm{k}$ & $\ln \mathrm{k}$ \\
\hline $\mathrm{A} 1$ & $5^{\circ} \mathrm{C}$ & 278 & 0,0036 & 4,23 & 1,44277 \\
$\mathrm{~A} 2$ & $10^{\circ} \mathrm{C}$ & 283 & 0,00353 & 4,20 & 1,43613 \\
$\mathrm{~A} 3$ & $20^{\circ} \mathrm{C}$ & 293,00 & 0,00341 & 8,93 & 2,18964 \\
\hline
\end{tabular}


Tabel 4. Hubungan 1/T dengan nilai k pada brokoli tanpa kemasan

\begin{tabular}{cccccc}
\hline Perlakuan & Suhu ${ }^{0} \mathrm{C}$ & Kelvin & $1 / \mathrm{T}$ & $\mathrm{k}$ & $\ln \mathrm{k}$ \\
\hline $\mathrm{B} 1$ & $5^{\circ} \mathrm{C}$ & 278 & 0,00360 & 4,96 & 1,60141 \\
$\mathrm{~B} 2$ & $10^{\circ} \mathrm{C}$ & 283 & 0,00353 & 5,54 & 1,71199 \\
$\mathrm{~B} 3$ & $20^{\circ} \mathrm{C}$ & 293 & 0,00341 & 13,93 & 2,63404 \\
\hline
\end{tabular}

Nilai k dan 1/T yang sudah diperoleh maka selanjutnya diplotkan pada grafik. Grafik dari hubungan $\mathrm{k}$ sebagai koordinat y dengan $1 / \mathrm{T}$ sebagai absis $\mathrm{x}$, akan memberikan persamaan garis lurus $y=a x+b$. Untuk Ea/R sama dengan a sedangkan untuk $k 0$ sama dengan $b$. Grafik hubungan $\mathrm{k}$ dan $1 / \mathrm{T}$

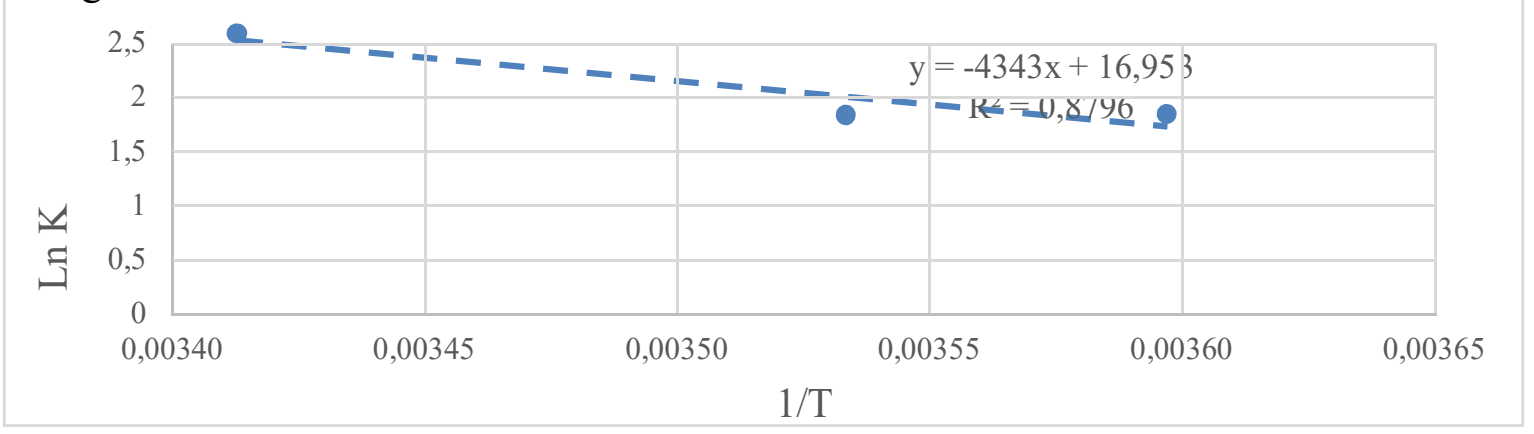

Gambar 1. Plot Arrhenius hubungan k dan 1/T pada brokoli dengan kemasan

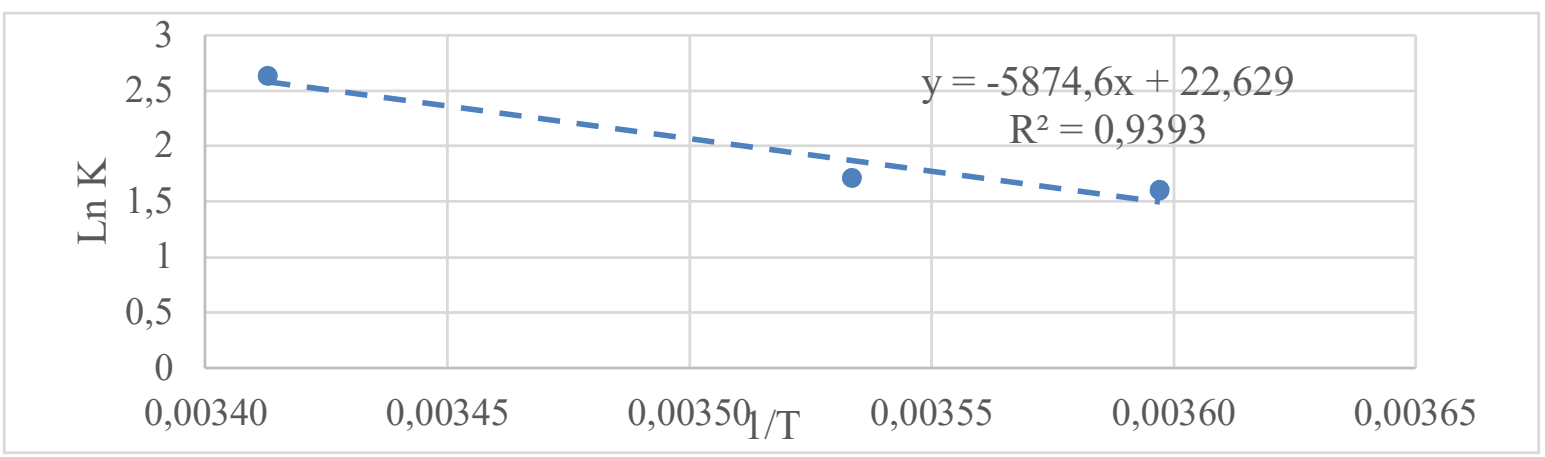

Gambar 2. Plot Arrhenius hubungan k dan 1/T pada brokoli tanpa kemasan

1. Brokoli di kemas dengan kemasan Streat Film

Maka didapatkan model (dengan kemasan $)=23045936,01 \mathrm{e}^{\wedge}(4343(1 / \mathrm{T}))$.

2. Brokoli tanpa di kemas

Maka didapatkan model $($ tanpa kemasan $)=6724342580 \llbracket \mathrm{e} \rrbracket \wedge(22.629(1 / \mathrm{T}))$.

\section{Energi Aktivasi}

Martyani dkk, (2013). menyatakan terdapat istilah energi aktivasi. Energi aktivasi adalah energi minimum yang dibutuhkan oleh suatu reaksi kimia agar dapat berlangsung. Energi aktivasi memiliki simbol atau lambang Ea dengan E menotasikan energi dan a 
menotasikan aktivasi. Kata aktivasi memiliki makna bahwa suatu reaksi kimia membutuhkan tambahan energi untuk dapat berlangsung..

\section{Simulasi Model Laju Penurunan Kadar Vitamin C (Asam Askobat) selama Penyimpanan Brokoli}

Setelah didapat nilai k maka selanjutnya untuk mendapatkan nilai model dari penyimpanan dengan kemasan dan tanpa kemasan pada setiap perlakuan suhu yaitu mencari model pendugaan penurunan brokoli selama penyimpanan. Didapatkan nilai $\ln \mathrm{k} 0$ dan nilai $\mathrm{k} 0$, nilai $\mathrm{k} 0$ merupakan exponensial ln k0 maka didapatkan modelnya sebagai berikut : Hasil model pendugaan laju penurunan Vitamin C (Asam askorbat) brokoli dengan kemasan dan disimpan pada suhu $5^{\circ} \mathrm{C}$, penurunan Vitamin C (Asam askorbat) brokoli berkurang sedikit dan bertahan 21 hari, sedangkan penurunan Vitamin C (Asam askorbat) brokoli jauh berkurang disimpan pada suhu $5^{\circ} \mathrm{C}$ tanpa kemasan hanya bertahan 18 hari. Penyimpanan brokoli pada suhu $10^{\circ} \mathrm{C}$ dengan kemasan bertahan 21 hari dan brokoli tanpa kemasan disimpan pada suhu yang sama hanya bertahan 15 hari. Pada penyimpanan suhu $20^{\circ} \mathrm{C}$ dengan kemasan hanya bertahan 9 hari sedang tanpa kemasan hanya bertahan 6 hari, hal menunjukan penyimpanan terbaik pada suhu $5^{\circ} \mathrm{C}$ dengan kemasan dengan penurunan Vitamin $\mathrm{C}$ (asam askobat) terendah dibandingkan dengan lainnya.

\section{Validasi Model Laju Penurunan Kadar Vitamin C (Asam Askobat) brokoli selama Penyimpanan}

Validasi model dapat dilakukan dengan membandingkan antara data yang diperoleh pada data dilaboratorium (data aktual) dengan data yang dihasilkan dari model, gambar dibawah ini merupakan hubungan Vitamin C (Asam Askorbat) aktual dengan Vitamin C (Asam Askorbat) model pada penyimpanan suhu $5^{\circ} \mathrm{C}, 10^{\circ} \mathrm{C}$ dan $20^{\circ} \mathrm{C}$ dengan kemasan dan tanpa kemasan.

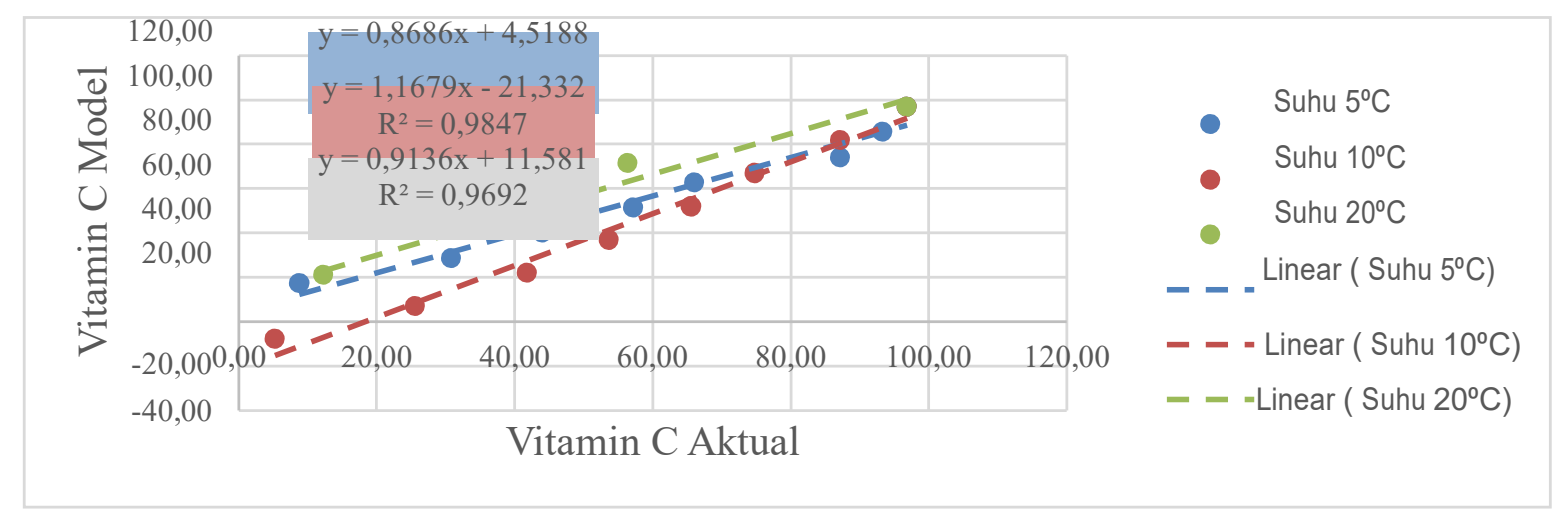

Gambar 3. Grafik kandungan Vitamin C (Asam Askobat) aktual dengan model brokoli kemasan disimpan pada suhu $5^{\circ} \mathrm{C}, 10^{\circ} \mathrm{C}$ dan $20^{\circ} \mathrm{C}$. 


\section{KESIMPULAN DAN SARAN}

\section{Kesimpulan}

Berdasarkan hasil dan pembahasan, maka dapat diambil kesimpulan sebagai berikut:

1. Model Pendugaan umur simpan berdasarkan asam askorbat brokoli dengan kemasan yaitu $\mathrm{k}=$ $23045936,01 e^{\left.4343()_{T}\right)^{-}}$, dan untuk brokoli tanpa kemasan $\mathrm{k}=6724342580 e^{22.629\left(_{T}\right)^{-}}{ }^{\frac{1}{}}$

2. Perlakuan terbaik pada penelitian ini yang mampu mempertahankan mutu simpan brokoli dan memiliki umur simpan yang lama, yaitu penyimpanan pada suhu $5^{\circ} \mathrm{C}$ dengan berdasarkan parameter susut bobot terendah sebesar $11,5 \%$, tingkat kekerasan tertinggi sebesar 0,7 $\mathrm{kg} / \mathrm{cm}^{2}$, penurunan kandungan asam askorbat sebesar $8,80 \mathrm{mg} / 100 \mathrm{gr}$, dan penurunan klorofil sebesar $0,35 \mathrm{mg} / \mathrm{gr}$.

Saran

Untuk Penelitian selanjutnya sebaiknya melakukan pengujian terhadap Vitamin A.

\section{DAFTAR PUSTAKA}

Citrosomo,S.S 1984. Botani Umum 2. Angkasa Bandung

Husna, I., 2008. Skripsi: Pengaruh Suhu Penyimpanan dan Pengemasan Terhadap Kesegaran Brokoli (Brassica oleraceae L var. Royal green ). Jurusan Biologi

Safaryani, N., Haryanti. S., Hastuti. E. D. 2007. Jurnal Pengaruh Suhu dan Lama Penyimpanan terhadap Penurunan KadarVitamin C Brokoli (Brassica oleracea L). Laboratorium Biologi Struktur dan Fungsi Tumbuhan Jurusan Biologi FMIPA UNDIP. Vol. XV, No. 2, Oktober 2007

Syarief, R dan Halid, H. 1993. Teknologi Penyimpanan Pangan. IPB. Bogor

Putra, I. P., Utama, S. M. I., Pudja, P. R. A. I. 2015.Pengaruh Pemberian uap Etanol dan suhu Penyimanan terhadap Mutu da masa simpan Brokoli (Basisca oleracea L. Var. Italica). Fakultas Teknik Pertanian UNUD.

Pantastico, E.B. 1997. Fisiologi Pasca Panen: Penangan dan Pemanfaatan Buah-Buahan dan SayurSayuran Tropika dan Sub Tropika. UGM Press. Yogyakarta

Winarno, F.G. 2000. Teknoloi Pasca Panen Jamur, Pengawetan dan Pengolahannya. Makalah Penelitian Budidaya Jamur Kayu. Kerjasama Mbrio Food Laboratory dengan pusbangtepa LPM IPB. Bogor. 